\title{
Knowledge levels among elderly people with Diabetes Mellitus concerning COVID-19: an educational intervention via a teleservice
}

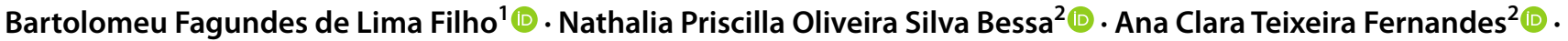 \\ Íkaro Felipe da Silva Patrício ${ }^{2}$ - Nadja de Oliveira Alves ${ }^{2}$ (D) Fabricia Azevedo da Costa Cavalcanti ${ }^{2}$ (i)
}

Received: 8 June 2020 / Accepted: 16 July 2020 / Published online: 4 August 2020

○) Springer-Verlag Italia S.r.l., part of Springer Nature 2020

\begin{abstract}
Aim To investigate knowledge levels concerning COVID-19 in elderly patients with T2DM.

Methods This cross-sectional, quantitative, observational, and descriptive study was undertaken among elderly individuals with T2DM involved in a body balance rehabilitation program that had been suspended due to social isolation. The study participants comprised elderly individuals with T2DM, contactable using fixed or mobile telephones. Data concerning participants' socioeconomic variables and knowledge of COVID-19 were collated, using a Brazil Ministry of Health guidelines checklist. Mann-Whitney and Spearman's correlation tests were used to analyze their responses.

Results Of 30 elderly participants, $76.7 \%$ were women and $63.3 \%$ were married. The average age was $69.96 \pm 4.46$ years. The most cited information medium was television (96.6\%). Of a possible 24 correct responses on the checklist, the median correct response score was 7.5. No significant relationship was observed between the total checklist score and the variables studied. Conclusion Elderly participants did not have in-depth knowledge concerning COVID-19, which suggests that their knowledge sources may be deficient or that their capacity to retain information was inadequate.
\end{abstract}

Keyword Telehealth · Type 2 diabetes mellitus · Elderly · COVID-19

\section{Introduction}

Type 2 Diabetes Mellitus (T2DM) is an important complication of COVID-19. According to survey results involving 7,337 SARS-CoV-2-infected patients in China, a diagnosis of T2DM significantly increased the risk of mortality in patients hospitalized with COVID-19 [1], as patients with T2DM are generally more susceptible to infections, including infections involving the respiratory tract [2].

A patient with T2DM may develop a more severe manifestation of COVID-19 due to excess body fat tissue, which

This article belongs to the topical collection Health Education and Psycho-Social Aspects, managed by Massimo Porta and Marina Trento.

Bartolomeu Fagundes de Lima Filho

bartolomeu_fagundes2@hotmail.com

1 Federal University of Rio Grande Do Norte (UFRN), Av. Senador Salgado Filho, 3000, Campus Universitário, Natal 59078-970, Brazil

2 Federal University of Rio Grande Do Norte (UFRN), Natal, Brazil increases the inflammatory and chronic pro-oxidative state in the body, resulting in negative effects on blood glucose [3]. Poor blood glucose control and hyperglycemia decrease immunity, which increases the risk of mortality due to COVID-19. In addition, an elderly patient with T2DM and SARS-CoV-2 infection may have severe kidney complications and cardiovascular and pulmonary diseases; therefore, particular attention is needed when treating and managing this high-risk patient group [4].

However, due to social isolation and social distancing measures, blood glucose control, and quality of life issues for elderly patients with T2DM have become more challenging, especially for those with other chronic diseases. Stoian et al. [4] proposed: (1) the elaboration of a digital medical record, which could directly send information, questions, and glycemic data from users to health professionals; (2) telephone contact involving an automated answering service tailored to questions asked by the user, and; (3) the use of telemedicine via videoconferencing [4].

Telehealth, telemedicine, telemarketing, and eHealth are frequently used terms to describe the use of information and communication technologies that provide health services at 
a distance in different areas. They allow screening and act as an aid to diagnostics, and promote interventions, protection, and health education. These technologies have been reported to be ideal during health emergencies in relation to communicable diseases, such as COVID-19 [5, 6]. A call center can coordinate the most diverse types of communication, ranging from lectures via videoconferencing for permanent education and inter-consultation, to phone calls, messages via cell phones, internet messaging platforms, videos, or satellite messages [5].

In patients with COVID-19 or among those at risk of SARS-CoV-2 infection, a call center can assist with remote assessments and care delivery. For non-infected individuals, especially those at higher risk of infection (for example, elderly people with preexisting medical conditions), a call center can provide convenient access to guidelines that should be followed during a pandemic, and provide routine care information without risking exposure to a hospital or any other congested health service with high exposure [7]. This study aimed to investigate knowledge levels among elderly individuals with T2DM in relation to COVID-19, through an educational intervention via a call center.

\section{Methodology}

This was a cross-sectional, observational, quantitative, and descriptive study. The study design was approved by the Ethics Committee in Research with Humans of the Hospital Universitário Onofre Lopes (HUOL) linked to the Federal University of Rio Grande do Norte (UFRN) (No: 3.084.420).

\section{Population}

In undertaking this study, we consulted a list of participants from the "Influence of a virtual reality protocol on the body balance of elderly people with type 2 Diabetes Mellitus: a randomized controlled clinical trial" project, who resided in the metropolitan area of Natal, Rio Grande do Norte, Brazil. All 38 participants in the mentioned project were contacted to participate in this study.

\section{Sample and eligibility criteria}

The sample population was drawn from those enrolled in the project described above. Our study participants comprised elderly individuals (aged 65-75 years) with a clinical diagnosis of T2DM according to the American Diabetes Association [8] who had been participating in body balance rehabilitation at the Laboratory of Technological Innovation in Health of the HUOL/UFRN and who had a telephone contact (fixed or mobile). Elderly individuals were excluded from the study if they did not respond to any of five attempts to make telephone contact, or who had hearing loss and did not have an accompanying caregiver who could receive guidance over the phone. Participants were asked at the beginning of the call whether they would like to participate in the survey. Everyone agreed.

\section{Instruments}

Sociodemographic data (sex, age, marital status, education, income, social participation, and housing arrangement) were obtained through a structured questionnaire, in the form of an interview.

Regarding the level of knowledge about COVID-19, a checklist was prepared based on data provided by the Brazil Ministry of Health (MOH), as shown in Table 1. No data were collected concerning "diagnosis," "information for travelers" and "if the individual becomes ill," to reduce the number of responses and because most of these matters had previously been clarified.

Scores were assigned, with one point added for each correct participant response. Possible scores were as follows: symptoms ( $0-5$ points); forms of transmission ( $0-6$ points), and; preventive measures ( $0-13$ points). The total score was the sum of the points acquired by the participant, ranging from 0 to 24 . The higher the score, the greater the level of COVID-19 knowledge. There was no specific cutoff point because a checklist from the Ministry of Health was used. Participants who cited symptoms different from those listed by the Ministry of Health were not scored. Otherwise, the symptoms were recorded, and the individual received guidance during the call.

\section{Procedures for obtaining data}

The elderly participants were contacted by an appropriately trained and qualified physiotherapy undergraduate student who conducted the telephone interviews during business hours. After identification and consent, participants were informed that they were part of the COVID-19 risk group because they are elderly and because they are diabetic. After, participants were questioned concerning their socioeconomic status.

Participants were asked to indicate whether they had obtained information concerning COVID-19 or SARSCoV-2 infection, and through what means of communication. Participants were asked to indicate what they knew about the symptoms, forms of transmission, and preventive measures concerning COVID-19. When the participants gave incorrect information, the interviewer provided accurate information, as well as adding any further relevant 
Table 1 Checklist of COVID-19 guidelines provided by the call center

\begin{tabular}{lll}
\hline Symptoms & Ways of transmission & Prevention measures \\
\hline Cough & Handshake touch & Wash hands with soap and water or with 70\% gel alcohol \\
Fever & Droplets of saliva & When coughing or sneezing, cover your nose and mouth with \\
Coryza & Sneeze & a handkerchief or your arm, not your hands \\
Sore throat & Cough & Avoid touching eyes, nose, and mouth with unwashed hands \\
Difficulty breathing & Catarrh & Maintain a minimum 2 m distance from anyone; \\
& Contaminated objects or surfaces, such as cell phones, & Avoid physical contact with people who do not live in your \\
& tables, door handles, toys, or computer keyboards & home \\
& & When ill, avoid physical contact with other people, includ- \\
& ing inside your own home, and stay at home until you your \\
& health improves \\
& Frequently sanitize children's cell phones and toys \\
& Do not share personal items, such as cutlery, towels, plates, \\
& and glasses \\
& Keep your environment clean and well ventilated; \\
& Avoid unnecessary circulation in the streets, churches, or in \\
& supermarkets, and banks \\
& Take plenty of rest and eat healthily \\
& Use fabric masks when leaving your home, changing them \\
& every $2 \mathrm{~h}$ \\
\hline
\end{tabular}

Source: Brazil Ministry of Health, 2020 Available at: < https://coronavirus.saude.gov.br/sobre-a-doenca\#se-eu-ficar-doente >

information not been previously mentioned by the participant. The calls lasted about $10-12 \mathrm{~min}$.

\section{Statistical analysis}

Data were analyzed using SPSS software (version 20.0, IBM, New York, USA), and the level of significance was set at $5 \%$ for statistical tests. Descriptive statistics (arithmetic mean, standard deviation, median, minimum, and maximum values, and $95 \%$ confidence intervals) were calculated.

Using a Shapiro-Wilk test, the dependent variable "total checklist score" was confirmed to be non-parametric. A Mann-Whitney test was used to compare the "total checklist score" and sociodemographic variables. Spearman's correlation test was used to correlate the "total checklist score" with age.

\section{Results}

Of 38 patients contacted, 30 elderly individuals (women; $n=23,76.7 \%$ ) answered the telephone and agreed to participate in this study. The average age was $69.96 \pm 4.46$ years (age range, 65 years-79 years), 63.3\% were married, and the average number of years spent in education was 8.16 $( \pm 5.81)$ years. Most of the sample $(56.7 \%)$ had completed primary education. The average income was $€ 585.08$ $( \pm 577,45)$, and their income was predominantly derived from 1 to 2 minimum wages (in Brazil). In total, $50 \%$ of the respondents participated in community activities. All study participants reported living with family members.

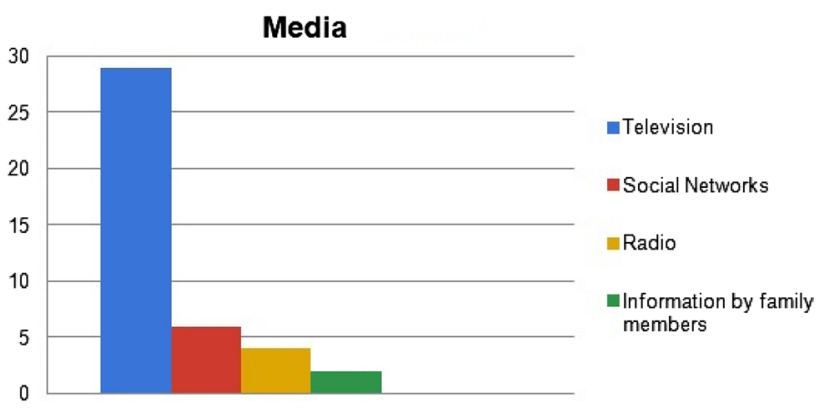

Fig.1 Sources of information concerning COVID-19 among elderly participants with T2DM. Source: Authors, 2020

Regarding the most used medium to obtain information concerning COVID-19, Fig. 1 shows that 29 of 30 participants reported receiving information from the television.

Concerning items derived from the Brazil MOH checklist, each variable may or may not have been mentioned by a participant during the telephone interview. Among items relating to COVID-19 symptoms, fever was most frequently cited $(n=23,76.7 \%)$. In terms of contamination, "touch or handshake" was the most cited form of transmission $(n=23$, $76.7 \%$ ). In terms of prevention, hand hygiene was the most cited item $(n=27,90.0 \%)$. Table 2 represents the variables studied and the number of individuals who mentioned that characteristic, with their respective percentage.

The total checklist score concerning all the variables showed an average of $7.73( \pm 1.61)$ points (range, 5-12). The Mann-Whitney U-test showed no significant difference between socioeconomic variables and total checklist scores in terms of sex $(p=0.56)$, marital status $(p=0.49)$, education 
Table 2 Checklist items and participant responses Source: Author, Natal/RN, 2020

\begin{tabular}{ll}
\hline Feature & $n(\%)$ \\
\hline Symptoms & \\
Cough & $13(43 \%)$ \\
Fever & $23(77 \%)$ \\
Coryza & $04(13 \%)$ \\
Sore throat & $08(27 \%)$ \\
Difficulty breathing & $16(53 \%)$ \\
Forms of transmission & \\
Handshake touch & $23(77 \%)$ \\
Droplets of saliva & $10(33 \%)$ \\
Splash & $10(33 \%)$ \\
Cough & $09(30 \%)$ \\
Phlegm & 0 \\
Contaminated objects or surfaces & $05(17 \%)$ \\
Prevention forms & \\
Wash hands and sanitize with alcohol & $27(90 \%)$ \\
Cover nose and mouth when sneezing & $01(03 \%)$ \\
Avoid touching your eyes, nose, and mouth & $01(03 \%)$ \\
If you touch your face, wash your hands immediately & $09(30 \%)$ \\
Avoid contact with people who do not live with you & $13(43 \%)$ \\
Maintain a 2-m distance from other people & $08(27 \%)$ \\
If you are sick, isolate yourself at home & $02(07 \%)$ \\
Sanitize children's cell phones and toys & $04(13 \%)$ \\
Do not share personal items & $01(03 \%)$ \\
Keep your environment clean and airy & $04(13 \%)$ \\
Avoid unnecessary circulation & $17(57 \%)$ \\
Take plenty of rest and maintain a healthy diet & 0 \\
Use a fabric mask, changing it every $2 \mathrm{~h}$ & $24(80 \%)$ \\
\hline & \\
& \\
&
\end{tabular}

( $p=0.15)$, income $(p=0.16)$, social participation $(p=0.39)$, nor did the Spearman's correlation test show a significant difference in relation to age $(p=0.34)$.

\section{Discussion}

Healthcare provision during periods of social isolation and social distancing has been delivered remotely during the COVID-19 pandemic in Brazil and elsewhere worldwide. Call centers have been introduced into the health arena as a positive strategy to maintain contact with patients living remotely and without physical contact. Interventions undertaken via telephone calls can be effective in promoting health and enhancing knowledge.

The participants in our study had low levels of education, which may have impaired their access to information and hindered their self-care, in addition to making it difficult to adhere to the treatment required concerning their comorbidities. Becker (2017) suggested that telephone contact was an efficient means of health education for this vulnerable population [9], and it appears reasonable to continue with this type of care when aiming to clarify issues and challenges concerning COVID-19. In addition, telehealth was effective in improving glycemic control, blood pressure, and knowledge about type 2 diabetes mellitus in a clinical trial with diabetic and hypertensive elderly individuals [10]. Moreover, participants suffering from diabetes still see telehealth as a strategy capable of improving their quality of life [11].

In total, $56.7 \%$ of the participants reported living on one to two minimum wages, which revealed further vulnerability among these patients as their limited resources may have affected their access to medication. These data can help guide health management in controlling COVID-19 better through implementing more appropriately targeted public policies to reduce the health needs of patients with chronic diseases [12].

In terms of the 24 items derived from the Brazil MOH checklist, an average score of $7.73( \pm 1.61)$ points indicated that the elderly participants with T2DM in our study were not as well informed concerning COVID-19 as they should have been. The participant with the highest score correctly identified only 12 items, comprising $50 \%$ of the relevant information. This finding suggests that the means of communication used by elderly individuals to receive information concerning COVID-19 may not provide sufficient or accurate enough information to meet their needs during this period of social isolation. Television was found to be the most used information medium for the elderly participants in this study, which was similar to the findings of a study by Goodman-Casanova [13] that showed television was a major means of providing health information and social support.

Providing timely, sufficient, and accurate information can raise awareness among a population. In emergency situations involving disease outbreaks, epidemics, and pandemics, effective communication is essential, with the provision of accurate information more likely to help responsible agencies to take more effective measures [14].

During a health crisis, the public depends on the media to transmit accurate and updated information to make informed decisions regarding health protection behaviors. Thus, it is essential that reliable sources are available to provide assessments and recommendations $[15,16]$. However, the ease of access to multiple media, along with the consumption, dissemination, creation, and sharing of information, mainly through social media, can have serious negative implications. A total of $20 \%$ of the sample claimed that one way to obtain information about COVID-19 was through social networks. However, the large amount of information generated through social networks, some of which is inaccurate, can be confusing, making it difficult to differentiate accurate from inaccurate content and facilitating the proliferation of potentially erroneous conceptions $[17,18]$. 
While no significant relationship was found between age and the total checklist score, we observed low scores $(\leq 50 \%$ of the total score) among the participants. This relationship may be explained as due to the limited and higher age range among the participants and that such elderly individuals tend to recall less health information [19]. The ability to recall instructions is critical in adhering to health professionals' recommendations and can be influenced by various factors, such as the amount of information conveyed to a patient and the manner in which it is acquired, the duration of exposure, and whether numerous interruptions occur [20, 21].

Age has been reported to influence the level of information retention [22]. It has also been shown that if not used frequently, the learned content passes through the working memory and is then discarded whereas, if such content is used routinely, it reaches the long-term memory and is retained [23]. However, as the information volume increases, it becomes more difficult to recover relevant information [20].

The participants' socioeconomic level (education and income) was a further consideration as this factor is an important determinant of health and of health-related matters. A person's socioeconomic level plays a mediating role between staying in good health and acquiring effective health information in terms of facilitating health literacy, defined as the knowledge, motivation, and skills of a person to access, understand, evaluate, and apply information, and to make decisions in daily life in relation to care, prevention, and health promotion to maintain or improve that person's quality of life [24].

In this study, $56.7 \%$ of the elderly participants reported having completed primary or post-elementary education; however, no statistical difference was found in relation to the total checklist score $(p=0.15)$. It is possible that information transmitted to this population group may have been so simple that all the participants assimilated the knowledge in a similar way. A low socioeconomic status is considered a potential risk factor for low health literacy [25], and education is one of the main determinants of health literacy. However, it has been suggested that education levels determined according to the number of completed school years is not accurate in measuring an individual's true educational level, as it does not take into account the different cognitive skills of each individual [26]. Individuals with the same educational level may have different levels of cognitive skills, leading to differences in knowledge acquisition [26].

Despite the importance of public policies focused on combating coronavirus disease of 2019 , conflicting information is sometimes transmitted by the mainstream media, causing doubt and lack of factual knowledge in the population [27]. It is suggested that all of this, linked to fake news and the low level of education of the majority of elderly population across the country, generates confusing information, making it difficult for the elderly to fully comprehend the situation.

This study had some limitations. It can be difficult for elderly participants to answer telephone calls. Of the 38 participants we initially sought to contact, 8 did not answer our calls. The participants were also noted to be shy in their responses and some had difficulties in expressing themselves over the telephone. Another limitation is the absence of a group for comparison. With no comparison group, it is difficult to account for other factors that could explain the low scores.

In conclusion, our study showed that the elderly participants did not have in-depth knowledge concerning COVID19 , as we obtained an average of only $7.73( \pm 1.61)$ correct answers from a total of 24 questions. This finding suggests that the knowledge sources of these elderly participants may have been deficient or that their capacity to retain information was inadequate. Television was the most cited source of information, and the total checklist scores did not show any significant difference in terms of depressive symptoms and social variables among the participants. Therefore, we suggest that teleservice interventions be encouraged and new approaches developed to disseminate accurate information concerning COVID-19.

Acknowledgments To Coordenação de Aperfeiçoamento de Pessoal de Nível Superior - Brasil (CAPES) - Doctorate's degree scholarship, Finance Code 001.

Funding The authors have not declared a specific grant for this research from any funding agency in the public, commercial or not-for-profit sectors.

\section{Compliance with ethical standards}

Conflict of interest The authors declare that they have no conflict of interest.

Ethical standard statement The study followed the tenets of Helsinki Declaration and consent was obtained. The study design was approved by the Ethics Committee in Research with Humans of the Hospital Universitario Onofre Lopes (HUOL) linked to the Federal University of Rio Grande do Norte (UFRN) (No: 3.084.420).

Informed consent All patients were informed of the purpose of study and signed a consent form.

\section{References}

1. Zhu L, She ZG, Cheng X, Qin JJ, Zhang XJ, Cai J et al (2020) Association of blood glucose control and outcomes in patients with COVID-19 and pre-existing type 2 diabetes. Cell Metab. https://doi.org/10.1016/j.cmet.2020.04.021

2. Drucker DJ (2020) Coronavirus Infections and Type 2 Diabetes-Shared Pathways with Therapeutic Implications. Endocr Rev. https://doi.org/10.1210/endrev/bnaa011 
3. Yang JK, Feng Y, Yuan MY, Yuan SY, Fu HJ, Wu BY et al (2006) Plasma glucose levels and diabetes are independent predictors for mortality and morbidity in patients with SARS. Diabetic Med. https://doi.org/10.1111/j.1464-5491.2006.01861.x

4. Stoian AP, Banerjee Y, Rizvi AA, Rizzo M (2020) Diabetes and the COVID-19 pandemic: how insights from recent experience might guide future management. Metab Syndr Relat D. https:// doi.org/10.1089/met.2020.0037

5. Celes RS, Rossi TRA, Barros SGD, Santos CML, Cardoso C (2018) A telessaúde como estratégia de resposta do Estado revisão sistemática. Rev Panam Salud Publica. https://doi.org/10.26633/ RPSP.2018.84

6. Nilson LG, Maeyam MA, Dolny LL, Boing AF, Calvo MCM (2018) Telessaúde: da Implantação ao entendimento como tecnologia social. Rev Bras Tecnol Soc. https://doi.org/10.14210/ rbts.v5n1.p33-47

7. Smith AC, Thomas E, Snoswell CL, Haydon H, Mehrotra A, Clemensen J et al (2020) Telehealth for global emergencies: Implications for coronavirus disease 2019 (COVID-19). J Telemed Telecare. https://doi.org/10.1177/1357633X20916567

8. Gross JL, Silveiro SP, Camargo JL, Reichelt AJ, Azevedo MJD (2002) Diabetes melito: diagnóstico, classificação e avaliação do controle glicêmico. Arq Bras Endocrinol Metab. https://doi. org/10.1590/S0004-27302002000100004

9. Becker TAC, Teixeira CRDS, Zanetti ML, Pace AE, Almeida FA, Torquato MTDCG (2017) Effects of supportive telephone counseling in the metabolic control of elderly people with diabetes mellitus. Rev Bras Enferm. https://doi. org/10.1590/0034-7167-2017-0089

10. Wakefield BJ, Holman JE, Ray A, Scherubel M, Adams MR, Hills SL, Rosenthal GE (2012) Outcomes of a home telehealth intervention for patients with diabetes and hypertension. Telemed J E Health. https://doi.org/10.1089/tmj.2011.0237

11. Lee PA, Greenfield G, Pappas Y (2018) Patients' perception of using telehealth for type 2 diabetes management: a phenomenological study. BMC Health Serv Res. https://doi.org/10.1186/ s12913-018-3353-x

12. Basu S (2020) Non-communicable disease management in vulnerable patients during Covid-19. J Med Ethics. https://doi. org/10.20529/IJME.2020.041

13. Goodman-Casanova JM, Durá-Pérez E, Guzmán-Parra J, CuestaVargas A, Mayoral-Cleries F (2020) Telehealth home support during COVID-19 confinement: Survey study among communitydwelling older adults with mild cognitive impairment or mild dementia. JMIR Preprints. https://doi.org/10.2196/preprints.19434

14. Brasil (2020) Ministério da Saúde. Disponível em: https://www. saude.gov.br/ Accessed 7 May 2020.

15. Garfin DR, Silver RC, Holman EA (2020) The novel coronavirus (COVID-2019) outbreak: Amplification of public health consequences by media exposure. Health Psycho. https://doi. org $/ 10.1037 /$ hea0000875
16. Lachlan KA, Spence PR, Lin X, Najarian K, Del Greco M (2016) Mídias sociais e gerenciamento de crises: CERC, estratégias de pesquisa e conteúdo do Twitter. Comput Hum Behav. https://doi. org/10.1016/j.chb.2015.05.027

17. Júnior JHS, Raasch M, Soares JC, Sousa LVHA (2020) Da Desinformação ao Caos: uma análise das Fake News frente à pandemia do Coronavírus (COVID-19) no Brasil. Cad Prospecc. https://doi. org/10.9771/cp.v13i2\%2520COVID-19.35978

18. Junior JHS, Petroll MDLM, Rocha RA. Fake News e o Comportamento Online dos Eleitores nas Redes Sociais durante a Campanha Presidencial Brasileira de 2018. In: Anais do XXII SemeAd - Seminários em Administração. https://login.semea d.com.br/22semead/anais/arquivos/501.pdf Accessed 7 May 2020.

19. McDonald-Miszczak L, Neupert SD, Gutman G (2005) Youngerold and older-old adults' recall of medication instructions. Canadian J Aging / La Rev Cane Du Vieil. https://doi.org/10.1353/ cja.2006.0013

20. Ayotte BJ, Allaire JC, Bosworth H (2009) The associations of patient demographic characteristics and health information recall: the mediating role of health literacy. Cognit Neuropsychol. https ://doi.org/10.1080/13825580902741336

21. Pazin Filho A, Scarpelini S (2007) Estrutura de uma aula teórica I: conteúdo. Med (Ribeirao Preto). https://doi.org/10.11606/ issn.2176-7262.v40i1p17-27

22. Araújo ES, Jacob-Corteletti LCB, Abramides DVM, Freitas Alvarenga K (2015) Capacitação de agentes comunitários de saúde na área de saúde auditiva infantil: retenção da informação recebida. Rev CEFAC. https://doi.org/10.1590/1982-0216201511913

23. Wilson EA, Wolf MS (2009) Working memory and the design of health materials: a cognitive factors perspective. Patient Educ Couns. https://doi.org/10.1016/j.pec.2008.11.005

24. Sørensen K, Van den Broucke S, Fullam J, Doyle G, Pelikan J, Slonska Z, Brand H (2012) Health literacy and public health: a systematic review and integration of definitions and models. BMC Public Health. https://doi.org/10.1186/1471-2458-12-80

25. Sun X, She Y, Zeng Q, Wang Y, Du W, Wei N et al (2013) Determinants of health literacy and health behavior regarding infectious respiratory diseases: a pathway model. BMC Public Health. https ://doi.org/10.1186/1471-2458-13-261

26. Stormacq C, Van den Broucke S, Wosinski J (2019) Does health literacy mediate the relationship between socioeconomic status and health disparities? Integr Rev Health Promot Int. https://doi. org/10.1093/heapro/day062

27. Lancet T (2020) COVID-19 in Brazil: So what? Lancet (London, England) . https://doi.org/10.1016/S0140-6736(20)31095-3

Publisher's Note Springer Nature remains neutral with regard to jurisdictional claims in published maps and institutional affiliations. 